\title{
Equity and access: community based water management in urban poor communities: an Indian case study
}

\author{
B. Poricha \& B. Dasgupta \\ National Foundation for India, India
}

\begin{abstract}
India is urbanizing rapidly and two of the major issues grappling the urban habitats in India today are issues of water and sanitation. These issues affect the development of urban settlements. The assumption is that these are technical problems thereby technical solutions should be able to address the concern. However, water and sanitation issues are embedded in complex social realities. This is more accentuated in urban poor communities where there are resource, access and equity disparities within and also outside. One of the ways of ensuring sustainable and equitable access to water and sanitation is by facilitating social ownership and developing community based socio engineering and environmentally safe models by building peoples' organization and strengthening community governance structures. This paper attempts at sharing the need for community based water management systems to tackle water inequity issues in society by sharing a case study of 2 ongoing projects on Strengthening Community-Centric Governance through Integrated Water and Sanitation Management in urban Cuttack in the state of Orissa and in the periurban town of Delwara in Rajasthan, both in India. Strengthening participatory local self-governance and improving the quality of life of people through integrated water, sanitation and waste management interventions is the key approach to this model and the paper shares the insights and principles generated from the case studies.
\end{abstract}

Keywords: community, water governance, water management, equity, sustainable development, community participation, NGOs. 


\section{Introduction}

The World Health Organization and UNICEF report states that roughly one in eight of the world population do not have access to safe water and adequate sanitation, which is nearly two fifths of the world population. Nearly 1.4 million children die every year from diarrhoea and other water related diseases caused by unclean water and poor sanitation.

Water is critical for a society's development. Water plays a seminal role not only in sustainable development but also in reducing poverty. Poor need access to water for their survival and to further their livelihoods and water inaccessibility limits opportunities for them to develop their potential.

More often than not, addressing the water needs of the poor is often simplistically seen as a technology fit of only providing access to drinking water.

But today, poverty is understood and seen as complex, multidimensional and varied. This multidimensional perspective today provides a basis to understand the enhanced vision of safe water which is a delicate balance between social engineering and technology. Therefore, integrated approaches to development today have water as an important component of a poverty reduction strategy. Water and poverty have a close link and water management and participatory and inclusive governance need to be seen as tools for social transformation, changing unequal social relations and thereby impacting development (Asian Development Bank [1]).

The other important challenge is that the overuse of water resources has increased over the past decades reaching a point today where water shortages, pollution and water quality degradation are seriously affecting economic, political and social developments. Therefore, water needs to be recognized as a scarce resource and also as a critical agent for societal development. Therefore for the society at large, management of water resources becomes significant in the development agenda.

How societies manage their water resources is a complex but significant interrelationship between technological choices and the differentiated social categories of caste, class, gender aspects on the ground, especially in developing economies like India.

This paper attempts at understanding some of these socially complex concepts, developing an understanding of the relationship between water and society and in doing this the paper tries to develop a model for Poverty, Water and Development from a people's perspective in India by sharing some successful economically and socially viable models of community based water governance and management.

\section{The Indian context}

With rapidly increasing population, food production and industrialization, demand for usage of water is growing every year in India.

India's rapid development story is weighed in by water stresses. This is often an expression of poor water management. One of the predominant debates 
ongoing in India today on water is on equitable distribution- whether distribution of water should be privatized? This has serious implications in India where nearly 60 percent of the population is below poverty line i.e. earns less than 20 USD per day. It is in this context that community water management at the local and regional levels gains its relevance and importance.

Unless water resources are managed efficiently and judiciously and ensure equitable access to water by all sections of the population, water crises leading to poor health and sanitary conditions and water conflicts will keep increasing with every passing day. This is becoming more evident in urbanized and urbanizing areas where the water availability and accessibility is way below accepted figures especially with respect to urban poor.

India has one of the largest and fastest growing populations in the world. As one of the fastest growing economies, our cities are also undergoing rapid growth. The rural - urban fringe is getting constantly consumed by the process and small towns, transitional settlements and fringe/ peri urban areas with substandard living conditions and slums are emerging as a cause of great concern.

In India, even though nearly 92 percent of the total urban settlements are constituted of, the small, medium and peri urban towns and centres, the economics of government expenditure for urban development is utilized predominantly for metros and class 1 cities. This over the years has resulted in meagre resources for the non metro townships to plan, develop and maintain their infrastructure. This has further lead to the emergence of slums in cramped, mismanaged urban settlements with poor quality of life for its residents and some of the critical factors affecting them are water, sanitation, waste management, education, employment etc (Kundu [2]).

The challenge in all of these is governance, management and lack of people's participation. Participation has been increasingly recognized as one of the most effective tool to achieve equity and sustainable development. For any development agenda to achieve increased equity, people need to come together and need to be active participants in the decision making processes.

Lack of people's involvement in the management of the local water resources in the past decades has led to a water crisis today. The rivers, lakes, and the ground table are shrinking and also becoming polluted. The Millennium Development Goals and the international development agenda clearly states access to potable water and sustainable usage of natural resources as a clear agenda for sustainable development, poverty and enhanced well being. India is urbanizing speedily. Small towns, peri urban/ mofussil habitats and small urban agglomerations are rapidly growing and been in increasing the load on basic infrastructure and natural resources. Growth of urban poor communities, resettlement colonies, unplanned layouts have lead to poor living conditions. They are most vulnerable to factors that disrupt their life and livelihoods. Non inclusive, non participatory governance mechanisms and inefficient water management systems add to this vulnerability index of the poor. Studies demonstrate that the provision of water and sanitation in low income and poor neighbourhoods is fundamental to meeting the basic needs of an urban 
population and inadequate water and sanitation are primary causes of diseases and ill health affecting the life and well being of the individual (Batchelor [3]).

The provision and the management of water supply and sanitation in independent India has been in the hands of the engineering departments of the formal local government agencies. As a result, the people abandoned the traditional methods of water usage and management practices. However their expectation of delivery of the quantity of potable water has also been raised, sometimes beyond the sustainable limits of the local environment. The delivery of these services has also been substandard. Some of the reasons are possibly lack of sufficient funds, insufficient manpower to design and execute all the necessary water supply and sanitation projects and also, often the lack of in depth knowledge of local conditions.

The geography of the country is varied. And so are the possible quantities of water available for use for consumption and irrigation. Simple engineering based solutions may not always be possible and economically viable everywhere. The government committed to the vision of providing potable water to all, has invested heavily in the last 15 years in providing common standpoints in the form of tube wells in all the semi urban settlements and also in villages. The case study in Orissa, demonstrates that this has not always been successful, as the water of the tube wells are not of potable quality. The people therefore use it for bathing and washing, while depending on the traditional wells for their drinking water.

The community based improved water and sanitation management in the 2 sites of Delwara in Rajasthan and Cuttack in Orissa, is an example of effective peoples participation and enhanced and sustainable water management. The project was initiated to improve people centric urban governance and strengthen the ability of the most disadvantaged sections of the society to contribute towards the overarching development goal and also sustain and manage their water resources.

\section{Participatory water management: a framework towards equity and social justice}

Water Governance as is understood is primarily building social support for equitable and sustainable development of the resource, based on comprehensive participatory planning and inclusive decision making processes. Water management is the operation and management of these resources by the local community.

The Government of India has formulated the National Water Policy for the development of a sustainable system for the management of the water resources. It outlines a broad framework for the tapping of the resource by different sectors of usage: irrigation, domestic consumption and industry. The various states of the country have developed more detailed water policy documents based on the specific conditions of the state. While these documents focus more on the technical issues involved in the management of the water resources, they do recognize the need to connect to the users (Mollinga and Tucker [4]). 
They also outline a participatory approach to water resource management through community and civil society organizations as an important component of water resource planning to ensure sustainability of a fast depleting resource.

However, mostly till date, NGOs have been involved by the engineering departments of the government to collect the relevant data of existing settlements needed for the planning of water and sanitation infrastructure related projects. The resultant large scale standard engineering based solutions are often expensive and due to the lack of funds, their installation is often delayed.

The case studies reveal that through participatory processes of engaging with the local communities, NGOs and civil society organisations working in the area can help improve existing systems and also develop new site specific suitable systems for water supply and sanitation. These more decentralized systems are generally less expensive to execute and the user community is intimately involved in their planning, execution and regular maintenance. This also helps to make them more environmentally sustainable as well.

Water management primarily requires systematic thinking on three critical aspects (Plummer and Slaymaker [5]).

- Technology

- Institution

- Knowledge system

Technology is very critical to any water resource management. Designing and operating water infrastructures with multi functional and optimal usage requires technical creativity for which understanding and respecting the user community is very seminal. Unless the technologists understand and include the user in their designing and decision making process in a participatory mode, the technology more often than not will fail in serving its purpose. Technology also has to understand the local context and be sensitive to social categories of gender, class, caste, poverty etc on the ground.

Institutional network of all the interest groups - state, providers, distributors, community and marginalized groups need to be addressed and strengthened. The existing institutional challenges that has resulted in the present state of affairs needs to be addressed and new arrangements need to be facilitated at community, local, regional and state levels.

The knowledge system presently in water is technology dominated. Water is not only a natural resource but is a social, political and economic determinant in India. As stated earlier, it bears a very close impact on poverty and therefore, water resources and solutions in India will require multidisciplinary approach and people working on this issue will need to think and act beyond their specified roles and disciplines to tackle the issue of water crisis and to ensure equitable access to water for all.

The principles underlying a participatory water management framework therefore has to be people centric, pro poor, gender sensitive, accountable, transparent, inclusive, equity driven, integrative, responsive, sustainable and communicative. 


\section{Community based water management}

Community based water management [6] in this paper has been understood as management of water resources by, of and for the people. In the two case studies illustrated below, it shows how and why ordinary people come together to resolve their local concerns. Development discourses and schools of thought say that a strengthened civil society facilitates a better governed, inclusive and just society.

The need for the intervention in Delwara in Rajasthan and Cuttack in Orissa, India was primarily based on

- poor and inadequate water infrastructure existing for the urban poor,

- inadequate norms for improving service delivery for this group of people

- Existing policies and programmes were found inadequate in addressing equity in water and sanitation efforts in urban areas.

The aim of the intervention was to empower ordinary people to transform their own lives. This was facilitated through regular interventions by the implementing agencies, facilitating organized, cohesive and empowered communities where common people were better placed to collaborate, cooperate, negotiate and leverage resources for local development. The ordinary citizen was engaged regularly both within and out of the group, to develop the concept of responsible citizenship to reflect, question and redefine themselves and their values in an effort to achieve a collective vision. Community involvement in water management was one of the ways of achieving this overarching vision.

Community participation was the key in these projects.

\subsection{Delwara: rejuvenation of a community water pond}

In India, traditionally, community water resources like ponds and wells are the key sources of water in any settlement - rural or urban. They not only fulfil the daily water needs of drinking, bathing and cleaning but also act as natural rechargers of the water table, leading to water availability for the region. Delwara, the site in discussion is a small peri urban township in a semi arid hilly region of Rajasthan. It is a small medieval town with a population of about 7000 people. It is densely built with houses lining both sides of narrow streets. The town is located near a small lake, the Palera, which is the main water source for the town and is also the primary water provider as the surface water source and as well as for recharging of hand pumps and wells. The town has a piped water supply system servicing about half the population, the water for which is pumped from one of the wells. The social pattern of Delwara is strongly stratified along caste lines, with people of the same caste living in the same neighbourhood or "padas". The rigidity of this system also contributes to inequitable distribution of water across neighbourhoods. An understanding of the social structure is important for the structuring of any community based development processes, 
especially in India, to ensure robust and strong community organization process and structures.

In 2004, when the project was initiated, the town had suffered 3 years of drought conditions during summer months when all the water sources dried up. The entry point activity, identified on the basis of a rigorous needs assessment in the field of water and sanitation, was the improvement of the availability of drinking water. Palera, the main pond had been dry in summer for a couple of years because of insufficient rainfall and because of the dilapidated condition of the pond feeders, the wells and aquifers of the settlement. The entire community's health, social and economic condition was suffering because of this inadequacy. Fifty percent of the households did not have access to sanitation and the same number had to travel long distances to fetch drinking water, leaving the women and young children with hardly any time for any other work.

This citizen engagement and integrated planning project initiated work on water and sanitation to ensure clean and potable water at the household level in Delwara. The citizens of Delwara collectively worked towards planning and executing a project for the desilting of the pond and for the repair and maintenance of the feeder channels. It is now 6 years, since the pond has been rejuvenated and it retains water throughout the year ensuring perennial water supply to the community. It has also recharged the neighbouring water sources in the village and the pond maintenance activities which are community driven are repeated every couple of years since 2006.

Some of the identified impacts have been

- No more droughts since then.

- Soil available from the desilting is not sold commercially, but used to fill the school playground and other low lying areas benefiting the community.

- $\quad$ Today the pond and the surrounding area are the largest open public space of Delwara and also the pride of the residents.

- Recognition of the importance of the pond maintenance process by the local official governance body - the panchayat. This has resulted in more work done in this field enhancing the water security of the town through public and private partnerships.

- It has also lead to planning and execution of other water supply projects for different parts of the town through partnerships of Government and peoples organizations.

Excited with this achievement the community went on to ensure the cleaning up and repair of the main drinking water source - a traditional step well. Today, the entire community comes together to clean this drinking water source periodically to ensure clean water and also to repair hand pumps, construct small water harvesting tanks and discuss on new water challenges facing the community. 

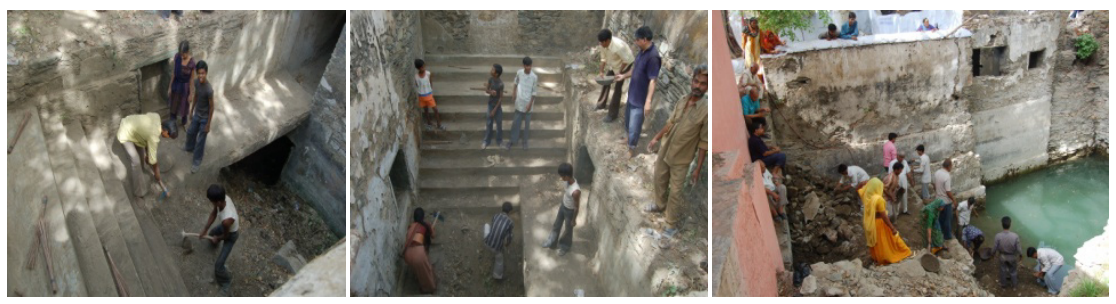

Figure 1: Community participation in progress in a community water tank.

\subsection{Cuttack: community inclusiveness - a water and sanitation intervention}

The project was started in 2009. The overall goal of the intervention was the improvement of the 4 peripheral urban poor dominated wards in the city of Cuttack in Orissa, India. These 4 wards are located in the outskirts of the town near a river called the Mahanadi. The settlements in the ward consist of small hamlets of about $300-1000$ people each, totalling a population of approximately 20000 people. The present character of these settlements is almost rural with single storied permanent and semi permanent homes loosely clustered. Though classified as urban, they have no access to either formal water supply system or to any sanitation and sewerage systems. Individual household toilets are practically nonexistent. It was an area with high poverty, unemployment and high health incidence rates.

This community based water and sanitation intervention was expected to enable ordinary people in society to add to the wellbeing of the deprived sections of the society. While doing so, they have been able to reduce health risks, facilitate greater empowerment, particularly of women and young people, foster social relationships, and enable and create a cleaner environment. This was possible only because the facilitating NGO designed the intervention with the people in the centre.

The involvement of women was and is central to this project. Demand for these facilities came, in the first instance from women and it is women who have worked to sustain this demand. The community was organized into small inclusive groups comprising of women, youth, people with special abilities, children etc. The interventional activities were designed to address not only general health, hygiene and environmental issues but also problems specific to women and children.

The primary goal was to enhance the quality of life and a sense of well-being of the inhabitants through a participative and consensual planning process. Wellbeing was considered not only in economic terms but also as overall development, which included environmental and ecological conservation and better social relations with special focus on gender justice. The project was aimed to facilitate greater participation of citizens in managing their own civic needs and strengthen the formal institutions of self-governance.

Today, while the scope of the project is increasing with the response of the people, the Entry Point Activities have been an eye-opener in community 
participation and mobilisation methods. The models adopted show variations depending on the social character of the community.

- In the 4 settlements, it was found that the water of the deep tube wells and hand pumps provided by the government agencies, though adequate was not of potable quality as it had very high iron content. Here the focus of the project was on digging of some new wells and the improvement of the existing ones by introducing low cost technology which helped in reducing iron and making the water potable.

- A demonstrable community water filter was designed and constructed to ensure clean drinking water for residents. This is being managed primarily through children and youth groups who ensure awareness generation, cleanliness, right usage and maintenance of this water structure. These structures are specifically designed to conserve water, replenish the rapidly descending water table, and do not require significant energy inputs.

- To prevent the contamination of well water, the well was covered, the surrounding area paved to prevent stagnation of overflow water and small hand pumps connected to the well were installed. This has reduced the effort required to draw water from the wells. The women of the community have played the central role in this initiative.

- The construction of individual toilets was undertaken through women's self help groups. These toilet constructions have been designed to the best of capacities to be ecologically sustainable. Sanitation facilities were constructed from local materials. The finances were designed and managed between the user, the group and the NGO in a rotational manner so as to benefit the poorest women favourably.

The principal benefits of this project through the process of community participation are:

- A clean environment; Sanitation available to households in the privacy of their own homes to ensure better health

- Maintenance of the installed structures in good condition

- Potable drinking water for the community

- Equity in access

- Behavioural change and responsible citizenship amongst young people

- Economic and environmental benefits

- Building aspirations among common people towards a collective vision

By directly empowering the citizens (men, women and children) to pursue their own development, the model ensured that the development projects belonged to the community who therefore had an interest in their upkeep and are able to expand to other projects should they wish. Much emphasis had been placed in making the projects sustainable by involving the residents at every stage and by ensuring that they have a clear stake in the construction and 
maintenance processes. These community structures are essentially durable structures requiring only minimal maintenance. These constructions have been designed to be ecologically sustainable using local materials. Operation and maintenance of the same will be carried out by the citizens and user groups that benefit from them.
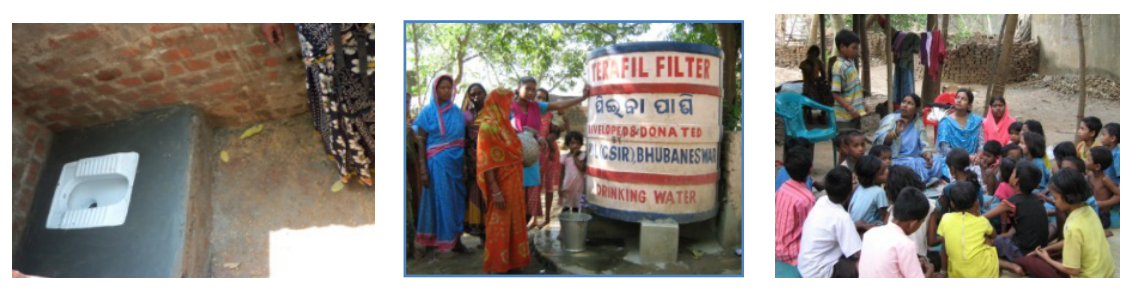

Figure 2: Community built water and sanitation structures.

\section{Conclusions}

Water management is the key to a healthy society. It also helps in poverty reduction and ensuring sustainable development. The case studies reveal that in the situation of the failure of service providing agencies the model of community based water management mechanism is a model and an approach, which could help in promoting equitable access to water resources. This could also ensure that scarce water is used more equitably, judiciously and efficiently, thereby leading to a more sustained utilization of water leading to a better environment. The local community is the best guide to its local resources, therefore, unless the community is prepared and empowered to understand and resolve their own local challenges; safe drinking water for all will remain at the theoretical level and have no sense of reality and social complexities in them.

The Indian experiment has shown that civil society initiatives and organizations have played a fundamental role in facilitating participation and community empowerment. This has enabled community based water management models to evolve and develop economical and ecologically viable models that address issues of access to water. Technology plays a critical role but it needs to be recognized that water is a social good and therefore civic participation is as much a critical factor to ensure access and equity to water by society as are technological solutions.

The two case studies in two different kinds of settlements demonstrate that participatory process can be adapted almost universally in India to achieve water security for all with a focus on the disadvantaged of the society.

\section{References}

[1] Asian Development Bank - "Water for all" series, 2002

[2] Kundu, Amitabh. In the name of urban poor - Access to basic services. New Delhi: Sage Publications, 1993 
[3] Batchelor Charles, Water governance Literature assessment, International institute for Environment and Development

[4] Mollinga, PP and Tucker, SP. Changing water Governance in India, Sawasjournal. Vol2, Issue 1

[5] Plummer, Janelle, and Slaymaker, Tom. Rethinking Governance in water services, Working Paper 284, 2007

[6] Reports - National Foundation for India, Arghyam and HDI 